(1)

CrossMark

\title{
A new breeze from an inspiring past: normality with multiple breath washout in school-aged children
}

\author{
Anne-Christianne Kentgens ${ }^{1,2}$, Marc Oppelaar ${ }^{1,2}$ and Peter Merkus ${ }^{1}$ \\ Affiliations: ${ }^{1}$ Division of Paediatric Pulmonology and Allergology, Amalia Children's Hospital, Radboud \\ University Medical Centre, Nijmegen, The Netherlands. ${ }^{2}$ These authors contributed equally.
}

Correspondence: Peter Merkus, Radboud University Nijmegen Medical Centre, Dept of Paediatrics, Division of Respiratory Medicine and Allergy, PO Box 9101, 6500 HB, The Netherlands. E-mail: peter.merkus radboudumc.nl

@ERSpublications

Multiple breath washout is likely to gain clinical relevance due to the recent availability of reference data. This may stimulate its clinical applicability in CF and other small airway diseases. http://bit.ly/ 2Wa72qE

Cite this article as: Kentgens A-C, Oppelaar M, Merkus P. A new breeze from an inspiring past: normality with multiple breath washout in school-aged children. Eur Respir J 2020; 55: 2000485 [https://doi.org/ 10.1183/13993003.00485-2020].

Often, the past can help us more than we realise. The European Respiratory Journal has, since its early childhood about 30 years ago, demonstrated that publication of reference values for various lung function tests is something that receives priority. Although one may argue that publication of reference values for lung function tests will not yield a Nobel Prize, everyone will agree that valid and reliable reference values are crucial for proper interpretation of test results of our patients and, therefore, indispensable for providing optimal care in respiratory medicine. In that sense, we owe the authors of such papers a lot.

One of the founding fathers of the European Respiratory Society, Philip Quanjer, was a true frontrunner in bringing together scientists and clinicians across the globe and producing the first collections of reference values $[1,2]$, something he continued to do for several decades, culminating in the Global Lung Function Initiative paper in 2012 [3], also inspiring others to collaborate globally to come to consensus statements on lung function quality, validity and standardisations [4]. A completely separate heritage from the past is the experience with and interest for single and multiple breath volume measurements using nitrogen as tracer gas, which was introduced even longer ago [5] and was used for patient care [6] and in epidemiological studies [7, 8].

But modern times and techniques have helped us even more, making life a lot easier. Nitrogen is back as a tracer gas in single and multiple breath washout techniques. In the old days, a nitrogen analyser had to be calibrated and yet linearity was difficult to achieve; nowadays we do not bother: we measure $\mathrm{CO}_{2}$ and oxygen, calculating rather than measuring the nitrogen content, in a fully computerised process; flows do not need calibration since the introduction of ultrasonic flow meters; and homemade equipment and slow desktops with floppy disks and small $40 \mathrm{Mb}$ hard disks have been replaced by high end, commercially available fast laptops with easy to use software programs. It is in this great era that we see that the nitrogen multiple breath washout technique $(\mathrm{MBW})$ is coming of age $[9,10]$ and especially that new reference values are published by in this issue of the European Respiratory Journal by ANAGnostopoulou et al. [11] for specific equipment and tracer gas, specifically for school-aged children. 
Until now the development and application of MBW was mainly focused on the field of cystic fibrosis (CF). It is hypothesised that the process of thickening mucus leading to obstructive lung disease and bronchiectasis begins in the smaller peripheral airways before progressing to the larger airways [12]. Newborn screening and multidisciplinary treatment strategies of the past decades have improved the prognosis of $\mathrm{CF}$, and the introduction of CFTR modulator drugs in 2012 has slowed down this progression of CF lung disease even further $[12,13]$. Considering that spirometry mainly measures larger airway pathology, the use of forced expiratory volume in $1 \mathrm{~s}$ is now limited as both a monitoring tool for early CF lung disease, as well as a primary outcome measure in new CFTR modulator trials [12, 14]. MBW, however, has shown to be more sensitive than spirometry to both (preclinical) small airway changes and therapy response in CFTR modulator trials $[12,14,15]$. Additionally, MBW is exclusive in its test feasibility in infants and pre-schoolers and continues to provide essential clinical information and novel pathophysiological insights in CF pulmonary disease development from infancy onwards [12, 14, 16]. The acquisition of pathophysiological knowledge of CF might be further enhanced by the combined use of MBW with techniques that describe other facets of lung function (e.g. magnetic resonance imaging) and by the availability of MBW reference data. Overall, it is therefore no surprise that CF has become a prominent MBW focus.

At the same time, the evolvements in CFTR modulator drugs raise the question of whether the future of MBW measurements is secure when it is almost solely used for CF. Due to the rapid advances and promising results of CFTR modulating drugs, CF may become a milder pulmonary disease in the future, which could imply that MBW parameters become abnormal at an older age than previously. Trials have shown that some CF patients are already recovering multiple diagnostic parameters to normal values in response to CFTR modulators [13]. On one side, this does emphasise the importance and need for solid MBW reference values for older ages as published in this issue [11]. On the other side, the former population is shrinking, and possibly the application of the MBW technique should not remain limited to CF.

In order to futureproof MBW, one could focus on the augmentation of its clinical applicability, because MBW can also be applied in other respiratory diseases $[17,18]$. Multiple studies support a role for MBW in (severe) asthma for additional in-depth airway assessment [17, 18]. More strongly, in COPD MBW was able to detect subclinical lung disease $[17,18]$. Also, in less prevalent lung diseases such as primary ciliary dyskinesia, bronchiolitis, bronchiolitis obliterans, pulmonary fibrosis and post-transplant allograft airway disease, MBW was shown to be more sensitive than other conventional pulmonary function tests [18-21]. Even though these populations could provide a much larger field of applicability, only few studies have been conducted in these populations or are currently registered in the North American and European clinical trial registries (https://clinicaltrials.gov and www.clinicaltrialsregister.eu). Furthermore, literature also suggests that combined use of MBW and imaging techniques for assessment of the aforementioned diseases could provide novel disease corresponding pathophysiological insights [22].

There are several additional ways to augment the clinical applicability of MBW, for example by (re) assessing the value of MBW outcomes. Firstly, one could examine whether lung function outcomes measured with MBW could replace established and more commonly used measurement techniques with a less favourable application profile (e.g. functional residual capacity measurement with MBW instead of the body plethysmography) [16]. Secondly, one could (re)assess the value of novel or alternative MBW parameters, such as volumetric capnographic (VCap) outcomes. VCap is a fast and easy lung function assessment technique of which one of the primary outcomes measured with MBW was shown to correlate with lung clearance index [23]. VCap outcomes have already been used for indications such as asthma, bronchopulmonary dysplasia and acute respiratory distress syndrome by assessing, amongst others, dead space ventilation, ventilation-perfusion matching, expirogram slopes and, herewith, airway obstruction and ventilation inhomogeneity [24-26]. Novel and alternative MBW outcomes may therefore be of use in CF and other respiratory diseases, and may thus facilitate lung function assessment in these diseases already from infancy on [25].

Finally, the clinical applicability could improve by enhancing the accessibility of the MBW technique, as MBW is not yet implemented on a large scale [27]. To date, several factors limit the use of MBW in clinical routine, and the European Respiratory Society/American Thoracic Society MBW consensus statement addresses, for example, the high proportion of test time consumption, the complexity of MBW equipment preparation and data processing as present day challenges [16]. Improving these factors may enhance test feasibility and thereby the attractivity of its use in clinical settings. Recent literature suggests that test duration can be shortened for example by using earlier test endpoints or even using prediction algorithms [28-30]. However, the attractivity of MBW as a tool in daily clinical routine may also increase when more data becomes available on how to interpret MBW data in a clinical setting, for example, on how to assess the quality, relevance and corresponding treatment consequences of MBW data measured for clinical purposes. 
In conclusion, $\mathrm{MBW}$ is an established tool for lung function assessment in CF that is expected to gain clinical relevance due to the increasing availability of healthy reference data and recent developments in its application field. The increasing prognosis of CF lung disease may imply that MBW may become a valuable tool for monitoring older patients. At the same time, the opportunity has come to also apply MBW in other respiratory disorders that affect small airways of younger and older children.

Conflict of interest: A-C. Kentgens reports grants (Swiss Government Excellence Scholarship) from The Swiss Confederation, Eidgenoössisches Department für Wirtschaft, Bildung und Forschung WBF, during the conduct of the study. M. Oppelaar has nothing to disclose. P. Merkus has nothing to disclose.

Support statement: This work was supported by Bundesbehörden der Schweizerischen Eidgenossenschaft (Swiss Government Excellence Scholarship). Funding information for this article has been deposited with the Crossref Funder Registry.

\section{References}

1 Quanjer PH, Stocks J, Polgar G, et al. Compilation of reference values for lung function measurements in children. Eur Respir J 1989; 2: Suppl. 4, 184S-261S.

2 Stocks J, Quanjer PH. Reference values for residual volume, functional residual capacity and total lung capacity. ATS Workshop on Lung Volume Measurements. Official Statement of The European Respiratory Society. Eur Respir J 1995; 8: 492-506.

3 Quanjer PH, Stanojevic S, Cole TJ, et al. Multi-ethnic reference values for spirometry for the 3-95-yr age range: the global lung function 2012 equations. Eur Respir J 2012; 40: 1324-1343.

4 Rosenfeld M, Allen J, Arets BH, et al. An official American Thoracic Society workshop report: optimal lung function tests for monitoring cystic fibrosis, bronchopulmonary dysplasia, and recurrent wheezing in children less than 6 years of age. Ann Am Thorac Soc 2013; 10: S1-S11.

5 Dubois AB, Botelho SY, Bedell GN, et al. A rapid plethysmographic method for measuring thoracic gas volume: a comparison with a nitrogen washout method for measuring functional residual capacity in normal subjects. J Clin Invest 1956; 35: 322-326.

6 Merkus PJ, Verver S, van Essen-Zandvliet EE, et al. Lung volumes measured by the forced rebreathing technique in children with airways obstruction. Eur Respir J 1992; 5: 879-886.

7 Merkus PJ, Borsboom GJ, Van Pelt W, et al. Growth of airways and air spaces in teenagers is related to sex but not to symptoms. J Appl Physiol 1993; 75: 2045-2053.

8 Sterk PJ, Quanjer PH, van Zomeren BC, et al. The single breath nitrogen test in epidemiological surveys; an appraisal. Bull Eur Physiopathol Respir 1981; 17: 381-397.

9 Aurora P, Gustafsson P, Bush A, et al. Multiple breath inert gas washout as a measure of ventilation distribution in children with cystic fibrosis. Thorax 2004; 59: 1068-1073.

10 Aurora P, Bush A, Gustafsson P, et al. Multiple-breath washout as a marker of lung disease in preschool children with cystic fibrosis. Am J Respir Crit Care Med 2005; 171: 249-256.

11 Anagnostopoulou P, Latzin P, Jensen R, et al. Normative data for multiple breath washout outcomes in school-aged Caucasian children. Eur Respir J 2020; 55: 1901302.

12 Ratjen F, Bell SC, Rowe SM, et al. Cystic fibrosis. Nat Rev Dis Primers 2015; 1: 15010.

13 Clancy JP. Rapid therapeutic advances in CFTR modulator science. Pediatr Pulmonol 2018; 53: S4-S11.

14 Perrem L, Rayment JH, Ratjen F. The lung clearance index as a monitoring tool in cystic fibrosis: ready for the clinic? Curr Opin Pulm Med 2018; 24: 579-585.

15 Horsley A. Lung clearance index in the assessment of airways disease. Respir Med 2009; 103: 793-799.

16 Robinson PD, Latzin P, Verbanck S, et al. Consensus statement for inert gas washout measurement using multiple- and single- breath tests. Eur Respir J 2013; 41: 507-522.

17 Robinson PD, Goldman MD, Gustafsson PM. Inert gas washout: theoretical background and clinical utility in respiratory disease. Respiration 2009; 78: 339-355.

18 Usemann J, Yammine S, Singer F, et al. Inert gas washout: background and application in various lung diseases. Swiss Med Wkly 2017; 147: w14483.

19 Kao JE, Zirbes JM, Conrad CK, et al. Lung clearance index is sensitive to small airway disease in pediatric lung transplant recipients. J Heart Lung Transplant 2017; 36: 980-984.

20 Stafler $\mathrm{P}$, Weinreb S, Mussaffi $\mathrm{H}$, et al. Feasibility of multiple breath washout measurements in infants with bronchiolitis: a pilot study. Pediatr Pulmonol 2017; 52: 763-770.

21 Nyilas S, Schreder T, Singer F, et al. Multiple breath washout: a new and promising lung function test for patients with idiopathic pulmonary fibrosis. Respirology 2018; 23: 764-770.

22 Nyilas S, Bauman G, Pusterla O, et al. Structural and functional lung impairment in primary ciliary dyskinesia. Assessment with magnetic resonance imaging and multiple breath washout in comparison to spirometry. Ann Am Thorac Soc 2018; 15: 1434-1442.

23 Fuchs SI, Junge S, Ellemunter $\mathrm{H}$, et al. Calculation of the capnographic index based on expiratory molar mass-volume-curves--a suitable tool to screen for cystic fibrosis lung disease. J Cyst Fibros 2013; 12: 277-283.

24 Cracco O, Degrugilliers L, Rames C, et al. Change in capnogram waveform is associated with bronchodilator response and asthma control in children. Pediatr Pulmonol 2019; 54: 698-705.

25 Fouzas S, Hacki C, Latzin P, et al. Volumetric capnography in infants with bronchopulmonary dysplasia. J Pediatr 2014; 164: 283-288

26 Verscheure S, Massion PB, Verschuren F, et al. Volumetric capnography: lessons from the past and current clinical applications. Crit Care 2016; 20: 184.

27 Singer F, Kieninger E, Abbas C, et al. Practicability of nitrogen multiple-breath washout measurements in a pediatric cystic fibrosis outpatient setting. Pediatr Pulmonol 2013; 48: 739-746. 
28 Shaw M, Oppelaar MC, Jensen R, et al. The utility of moment ratios and abbreviated endpoints of the multiple breath washout test in preschool children with cystic fibrosis. Pediatr Pulmonol 2020; 55: 649-653.

29 Gronbaek J, Hallas HW, Arianto L, et al. New timesaving predictor algorithm for multiple breath washout in adolescents. Pediatr Res 2016; 80: 49-53.

30 Yammine S, Singer F, Abbas C, et al. Multiple-breath washout measurements can be significantly shortened in children. Thorax 2013; 68: 586-587. 